\title{
RELACIONAMENTO CONJUGAL E TRANSIÇÃO PARA A COPARENTALIDADE: PERSPECTIVA \\ DA PSICOLOGIA POSITIVA
}

\author{
Laissa Eschiletti Prati* \\ Silvia Helena Koller**
}

\section{Resumo}

Este ensaio teórico-prático aborda a transição do sistema conjugal para a coparentalidade, além das implicações clínicas para a psicoterapia segundo a Psicologia Positiva. A coparentalidade engloba funções de cada membro do casal que se estendem além do âmbito biológico. Ela constitui-se em um rearranjo psíquico complexo que ocorre internamente e no espaço psicossocial. A transição de papéis é um processo considerado como crise situacional, pelo ajustamento às novas condiçôes, podendo trazer repercussões no relacionamento conjugal. $\mathrm{O}$ acompanhamento terapêutico pode ser um auxílio para uma melhor vivência nesta fase de reorganização. Neste contexto, encontra-se a Psicologia Positiva, que enfatiza os recursos e aspectos saudáveis dos que procuram atendimento. Entre os aspectos que podem surgir em terapia estão a mudança de relação com as famílias de origem, o aumento de interesses ou busca de novas possibilidades profissionais dos cônjuges e a coparentalidade em si mesma.

Palavras-chave: parentalidade; papéis parentais; casamento; conjugalidade; psicologia positiva.

\section{Abstract}

MARITAL RELATIONSHIP AND TRANSITION TO CO-PARENTING: POSITIVE PSYCHOLOGY APPROACH

This theoretical-practical essay approaches the marital system transition to coparenting relationship and some clinic implications for psychotherapy according to Positive Psychology

\footnotetext{
* Universidade Federal do Rio Grande do Sul.

** Universidade Federal do Rio Grande do Sul.
} 
approach. Coparenting relationship involves functions from each couple member that go beyond the biological domain. It creates a complex psychic reorganization that happens internally and in the psychosocial space. The role transition is a process considered a situational crisis, because an adjustment to the new conditions is needed, and it may generate repercussions in the couple relationship. A therapeutic process can help couples for a better experience of this period of reorganization. In this context, Positive Psychology tries to emphasize resources and healthy aspects of those that came to therapy. Aspects that may appear in therapy are changes in original family relationship, increase of interest or search for new professional possibilities and coparenting itself, among others.

Keywords: parenthood-status; parental roles; marriage; conjugality; positive psychology.

\section{INTRODUÇÃO}

O presente ensaio apresenta uma breve revisão da literatura sobre a transição do sistema conjugal após o nascimento do primeiro filho. Portanto, tem-se como objetivo estabelecer uma relação de coparentalidade, levando em conta a abordagem da Psicologia Positiva na psicoterapia. Ser pai ou ser mãe caracteriza-se pela vivência de um período de incertezas e desafios, envolvendo a necessidade de acesso a novos recursos e a flexibilidade para lidar com o imprevisível. A coparentalidade, compreendida como os aspectos que se referem aos cuidados com as crianças (Van Egeren \& Hawkins, 2004), exige negociações e alteraçôes no relacionamento conjugal. Esses movimentos se fazem cada vez mais presentes na prática clínica com adultos. Entre os aspectos que podem surgir no trabalho terapêutico em famílias e na coparentalidade, salientam-se o relacionamento com as famílias de origem, o aumento de interesses ou possibilidades profissionais dos cônjuges e os aspectos subjetivos acionados com a vivência da parentalidade.

Entre as abordagens possíveis da clínica está a Psicologia Positiva, que surgiu nos Estados Unidos no final da década de 90. Martin Seligman, um dos principais autores dessa abordagem, chamava a atenção para o fato de que a Psicologia vinha negligenciando o estudo dos aspectos virtuosos da natureza humana: a possibilidade de prevenção e os aspectos da clínica que valorizam os aspectos saudáveis do funcionamento dos que buscam ajuda. Seligman (2002) afirmou que a terapia positiva permitiria acessar a dupla missão da psicologia: recuperar o que está enfraquecido e fortalecer o que está forte. Portanto, a clínica apoiada na Psicologia Positiva caracteriza-se por buscar o fortalecimento dos aspectos saudáveis dos indivíduos, o reconhecimento de forças pessoais e o acesso a recursos que permitam uma mudança saudável (Paludo \& Koller, 2007). 


\section{O RELACIONAMENTo CONJUGal E A TRANSiÇÃo PARA A COPAREN- TALIDADE}

O funcionamento familiar é construído desde as primeiras relações do casal e tem profundas implicações nas futuras interações dele com seus filhos (Menezes, 2001). A necessidade de rearranjos familiares surge de forma mais concreta com a notícia da gravidez; momento em que se inicia a estruturação de espaço para a entrada de um novo membro no sistema, até então conjugal. Alguns aspectos, como o tom afetivo e a história construída até este momento pelo casal atuam, segundo Gee, Scott, Castellani e Cordova (2002), como preditores da satisfação conjugal posterior ao nascimento do bebê. Durante a gestação, os casais devem começar a lidar de forma mais direta com algumas regras de relacionamento, que podem ser ajustadas antes do nascimento da criança. Regras de relacionamento são interações inconscientes que se mantêm como padrão de comunicação entre os membros do sistema familiar (Féres-Carneiro, 1992). A gestação é compreendida, portanto, como um momento de preparação do casal para assumir os novos papéis que surgirão (Piccinini, Silva, Gonçalves, \& Lopes, 2004).

Com o nascimento do bebê, o casal depara-se com a necessidade concreta de ter que dividir os cuidados com a criança. A preocupação em acertar desencadeia negociações e desafia a estabilidade do casal. A diminuição do tempo do casal para si próprios e a necessidade de dividir tarefas, até então desconhecidas, gera uma necessidade de apoio e de busca por uma nova estrutura para este relacionamento. Essa redução do tempo para o próprio casal pode: (a) trazer dificuldades em lidar com problemas cotidianos; (b) medo de errar; (c) um sentimento de diminuição de intimidade (Ahlborg, Dahlöf, \& Hallberg, 2005).

Além disso, após o nascimento do bebê, a divisão de tarefas deixa de ser apenas discutida e planejada; passa a ocorrer em termos mais concretos e, algumas vezes, iminentes, acionando sentimentos novos em ambos os cônjuges. A responsabilidade compartilhada pode ou não ser diferenciada de forma substancial. $\mathrm{Na}$ diferenciação de papéis, a mulher, por exemplo, fica responsável por manter o bebê saudável fisicamente, enquanto o homem envolve-se em aspectos práticos que possibilitem conforto e proteção. Obviamente, isso não acontece em todos os casais. Há casos em que a mulher sente-se impedida, em função do desconforto físico e da ocupação com o bebê, de realizar as tarefas que antes desempenhava. Sendo assim, os cuidados com a casa, que exigem mais força física e que estavam principalmente sob sua responsabilidade, podem ser delegados ao homem. Por outro lado, o pai também pode envolver-se com os cuidados da criança e se empenhar em compartilhar com a esposa tarefas e preocupações. Atualmente, as mulheres 
reivindicam a participação do marido na criação das crianças e os próprios maridos, ao perceberem o prazer na intimidade proporcionado por esses cuidados com seu filho, também buscam se envolver com essas tarefas (Baratojo, Falceto, \& Giugliani, 2008). Ressalta-se, ainda, que os pais são referência para a estruturação e o desenvolvimento da criança, sendo fundamental a coerência entre as posturas adotadas por ambos para a construção de uma noção de identidade.

Visto isso, os cuidados diretos com o bebê, as questôes práticas referentes à nova organização familiar e os novos papéis assumidos pelo casal tornam necessária a construção de um espaço (interno e comunicacional) que permita aos cônjuges discutir uma prática que está em constante modificação. As alterações no casal, que ocorrem logo após o nascimento do bebê, influenciam de maneira fundamental a relação entre pais e filhos ao longo dos anos (McHale, Kuersten-Hogan, \& Rao, 2004). Esse período afeta a família como um todo e a cada um dos indivíduos de formas diferentes. Portanto, pode ser entendido como um momento de crise. Para Aguiar, Lago, Strassburger, Blaya e Campos (1993), crise é definida como um período de desorganização com sentimentos de desconforto (como ansiedade, medo, culpa ou vergonha) no qual uma pessoa não consegue superar as adversidades com seus meios habituais para a solução de problemas. Há uma sensação de impotência por não existirem outros recursos disponíveis para a reconstrução da estabilidade do ciclo de vida. A família extensa e as pessoas relevantes do grupo social são alguns dos elementos mais importantes da busca pela dissolução da crise.

Uma crise esperada/previsível do desenvolvimento humano, como o nascimento de uma criança, em geral faz com que indivíduos, casais, família extensa e comunidade respondam de forma diferente. Essa modificação no padrão das relações comumente permite que a família continue seu desenvolvimento, tendo renovadas suas forças e maturidade. Mas há famílias que passam por um período significativo de sofrimento e têm dificuldades de encontrar um novo padrão de relação saudável. Sendo assim, espera-se que profissionais, que atuem com as famílias e que tendem a manter uma visão positiva do percurso destas, busquem aspectos funcionais dentro deste emaranhado de mudanças.

Estudar a família a partir das suas etapas do ciclo vital não é novidade para os profissionais que atuam na clínica familiar (Carter \& McGoldrick, 1995; Pires, 2008; Pittman, 1994; Sattler, Eschiletti, Bem, \& Schaefer, 1999), pois esse conceito auxilia a descrever os processos esperados e previsíveis do desenvolvimento humano, incluindo processos críticos que demandam transformações pessoais e no sistema relacional. A partir deste entendimento advindo do ciclo vital, constata-se que há uma alteração intuitiva nos casais e famílias, adequando-se ao momento específico que estão vivendo (Menezes \& Lopes, 2007). 
O nascimento do primeiro filho do casal é exatamente um destes momentos. É exigida uma alteração em diversas relações (intra e interfamiliares). $\mathrm{O}$ conceito de coparentalidade pode auxiliar na reflexão sobre as várias alterações referentes ao ajuste conjugal no nascimento do primeiro filho. Alguns autores (Feinberg, 2002; McHale et al., 2004; Talbot \& McHale, 2004; Van Egeren \& Hawkins, 2004) sugerem, inclusive, que a coparentalidade viria como outra possibilidade de compreensão da dinâmica conjugal, que se estabelece nesse momento evolutivo.

Coparentalidade, portanto, difere dos conceitos de relacionamento conjugal, de relacionamento entre pai e filho e de sistema familiar. Ela apresenta características específicas que influenciam no desenvolvimento da criança e do sistema familiar em sua totalidade. Trata-se de um conceito complexo que se relaciona com diversas áreas do sistema familiar. Para circunscrevê-lo, a definição de limites externos (quem, o quê e quando) e internos (o quê) é necessária (Van Egeren \& Hawkins, 2004).

Geralmente, coparentalidade é definida como "as formas como os pais trabalham juntos no seu papel de pais” (Feinberg, 2002: 173). Contudo, não necessariamente a coparentalidade é exercida por um casal. Talbot e McHale (2004) ampliaram o conceito, afirmando que pode ser desenvolvida por dois ou mais adultos que trabalham juntos para o desenvolvimento de uma criança pela qual todos são responsáveis. Portanto, incluem-se aqui casais homo e heterossexuais, casados ou não, divorciados e também as díades mãe-avó ou qualquer outra configuração de adultos que dividam a responsabilidade por uma criança. De fato, a coparentalidade pode ser estudada inclusive quando um dos pais nunca tenha se envolvido diretamente com a criação do bebê (McHale et al., 2004). Com essa lógica de pensamento, passa a ser mais adequada a definição de coparentalidade proposta por Van Egeren e Hawkins (2004: 166): "uma relação de coparentalidade existe quando se espera, em comum consenso ou por normas sociais, que pelo menos dois indivíduos tenham responsabilidade conjunta pelo bem-estar de uma criança em particular" ". Portanto, o estabelecimento da coparentalidade requer, no mínimo, uma criança e dois adultos, pois é um processo triádico e multidirecional. Estudá-lo envolve captar as açôes que influenciam o casal e que dizem respeito às responsabilidades partilhadas relativas ao desenvolvimento e cuidados do bebê. A negociação de rotinas e estabelecimento de limites à família extensa também fazem parte do quebra-cabeça dinâmico que compõe tal contexto e suas relações. Sendo assim, para estudar a coparentalidade é fundamental investigar como o casal estabelece limites externos (quem faz que tarefa, o que deve ser feito e quando deve acontecer) e internos (o que se espera como resultado destas ações 
no cotidiano do casal) a fim de perceber sua aplicação no contexto de transição para a parentalidade (Van Egeren \& Hawkins, 2004).

A coparentalidade aparece efetivamente somente após o nascimento do bebê. As discussões pré-natais e as representações mentais sobre esta condição atuam apenas como preditores das relações do casal. Durante a gestação, casais desenvolvem representações mentais de si mesmos como pais e, consequentemente, da coparentalidade. Porém muitas decisões construídas nessa fase se alteram com a presença da criança. Entretanto, entender a coparentalidade somente como a divisão dos aspectos práticos de cuidado com a criança é uma perspectiva limitante das responsabilidades dos adultos (McHale et al., 2004). Estão presentes na coparentalidade tanto características individuais e de relacionamento, quanto habilidades para resolver problemas, manejo de conflitos e apoio mútuo para as atividades atribuídas a cada cônjuge (Van Egeren \& Hawkins, 2004). Pode-se tomar como exemplo: momentos nos quais um membro do casal interage com o(a) filho(a), valorizando ou desconstruindo o que foi definido pelo outro cônjuge, são relevantes na constituição da coparentalidade.

Feinberg (2002) propôs quatro componentes básicos da coparentalidade: 1) apoio versus desmerecimento do papel parental; 2) diferenças nas atitudes e valores quanto à criação dos filhos; 3) divisão de trabalho parental; e 4) administração de interações familiares, incluindo a exposição das crianças aos conflitos do casal.

O primeiro componente (apoio versus desmerecimento do papel parental) enfatiza a forma como os adultos se valorizam e se apoiam como pais. Envolve a afirmação da competência do outro, reconhecimento, respeito e manutenção das decisões do outro adulto no que se refere à criança.

$\mathrm{O}$ segundo aspecto (diferenças nas atitudes e valores quanto à criação dos filhos) fala das discordâncias do casal quanto à criação do bebê. Esse fator influencia diretamente a consistência de disciplina (incluindo famílias de origem) e surge como um preditor de problemas de comportamento da criança (Feinberg, 2002).

O terceiro componente está relacionado à divisão de tarefas e responsabilidades da rotina da criança. $\mathrm{O}$ casal precisa negociar sobre as atividades e funçôes de cada um com relação à criação dos filhos (quem dá banho, quem alimenta, por exemplo). Quando há um desequilíbrio nessa divisão, somada à dificuldade de renegociação, pode-se gerar insatisfação com relação ao parceiro. A percepção da mãe sobre a justiça nessa divisão, segundo Feinberg (2002), aparece como crucial para a satisfação conjugal.

Por fim, o quarto componente (administração de interações familiares) é composto por três aspectos: conflito, coalizão e equilíbrio. Um dos aspectos mais preocupantes são os casos nos quais os pais não conseguem manejar seus próprios 
conflitos, expondo a criança a situações de hostilidade. Ainda existem situações nas quais os pais criam coalizôes elou triangulaçôes, envolvendo as crianças nas soluções de seus desentendimentos. O equilíbrio refere-se, especificamente, à proporção de tempo que cada genitor engaja com a criança em situaçôes de triangulação. Nesses momentos, por exemplo, o pai pode, junto com os filhos, auxiliar a mãe com o jantar ao arrumar a mesa, ou conversar sobre um desenho realizado pelos filhos em conjunto com a mãe. O importante nas relações de equilíbrio é a possibilidade de ambos os pais conseguirem interagir com os filhos individualmente, mesmo ou com o outro cônjuge presente.

Existem outras quatro dimensões qualitativamente distintas na coparentalidade, segundo Van Egeren e Hawkins (2004), que se referem diretamente à interação conjugal: a solidariedade, o suporte, as fraquezas e as partilhas. A solidariedade evidencia-se através de expressões de acolhimento e emoções positivas durante interaçôes com ou sobre a criança, sentimentos que fazem o casal se aproximar como resultado de uma parentalidade compartilhada. O suporte envolve as estratégias adotadas por ambos os cônjuges, que auxiliam no alcance das metas estabelecidas por estes. As fraquezas, em contrapartida, são as açôes que impedem o parceiro de assumir seu papel ativo no desenvolvimento do filho e envolvem desrespeito e crítica às atividades assumidas pelo parceiro. Por fim, a partilha refere-se à mais ampla das dimensões da coparentalidade, englobando a divisão de tarefas entre os cônjuges e os sentimentos relacionados a essa organização.

Verifica-se que a aliança coparental pode ser especialmente relevante para o desenvolvimento do adulto, influenciando tanto o âmbito social quanto o cognitivo de cada membro do casal (McHale et al., 2004). A presença de dissonâncias no relacionamento conjugal é esperada, mas requer que o casal esteja atento e aprenda a lidar com as mesmas. Há pessoas que percebem essas dissonâncias e buscam construir um espaço de reciprocidade, constante e apoiador, com o objetivo principal de atender as necessidades e identificar os sentimentos do bebê. Nesses casos, existe uma estrutura externa (composta por estratégias de comunicação e negociação) que permite aos cônjuges entenderem e conversarem sobre a perspectiva do outro quanto aos cuidados com a criança. Em contraste, as possibilidades de crescimento são impedidas quando o casal assume uma posição dogmática de crítica, demonstrando-se inflexível.

Assumir os papéis definidos pela coparentalidade envolve, portanto, desafios para cada cônjuge. Instabilidades e reorganizaçôes refletem-se na vida de ambos e envolvem mudanças em diversos outros âmbitos, entre eles a satisfação conjugal, a comunicação, o afeto e a divisão de atividades (Van Egeren \& Hawkins, 2004). Em função de todas essas reorganizações, o momento do nascimento do bebê pode ser 
um bom momento para intervir no aprimoramento da relação coparental. Sendo assim, esse período, no qual ambos os cônjuges estão abertos a mudança, é uma boa oportunidade para a realização de um trabalho preventivo (Feinberg, 2002).

Logo, intervir nos aspectos práticos da criação de uma criança por ambos os pais, ou coparentalidade, pode ser uma porta de entrada para um trabalho clínico bem-sucedido. Além disso, trabalhar com expectativas e crenças que os casais apresentam sobre a coparentalidade pode ser compreendido como um trabalho preventivo (Feinberg, 2002). A Psicologia Positiva, por seu padrão de favorecimento ao que há de psicologicamente saudável preservado, parece ser uma boa escolha teórica para embasar uma abordagem terapêutica.

\section{A coparentalidade e a abordagem da Psicologia Positiva}

Como visto acima, o estudo da coparentalidade propiciou o acesso a uma área relacional bem definida e com potencial de mudança. Intervenções focadas na relação coparental podem gerar efeitos mais duradouros no sistema que busca apoio terapêutico. Tendo em vista que a interação coparental está se constituindo com o nascimento do primeiro bebê, existem flexibilidade e força suficientes para o surgimento de um sistema bem estruturado e possibilitador de desenvolvimento saudável (Feinberg, 2002; Menezes \& Lopes, 2007). Fatores de proteção e de risco podem ser identificados e antecipados favorecendo o desenvolvimento saudável da família. Dessa forma, intervençôes focadas na constituição da coparentalidade devem, portanto, fortalecer fatores de proteção das famílias, uma vez que aspectos positivos estão se constituindo na relação. Os riscos também são trabalhados para o fortalecimento das pessoas no período de mudanças e reajustes (Feinberg, 2002). Diante destas demandas, a Psicologia Positiva pode ter expressiva atuação nos processos terapêuticos.

A abordagem de atendimento ao casal com relação à coparentalidade apoiada na Psicologia Positiva enfatiza a funcionalidade dos sistemas no processo terapêutico. Embora seja uma proposta nova e em desenvolvimento, possibilita um maior enfoque à reavaliação das potencialidades humanas. Há uma mudança de foco por parte dos profissionais. Não é procurado o que não funciona, mas se amplia o que existe de melhor nas pessoas. A psicologia passa a ter o compromisso de (re)construir qualidades positivas, ampliando seu campo de atuação (Gillham \& Seligman, 1999). Volta-se a investigar o comum, o ordinário, o dia-a-dia e, nessa alteração de foco, resgatam-se possibilidades e recursos outrora pouco acionados pela família que passa por um período de crise. O nascimento do primeiro bebê 
cria, dentre outras coisas, um contexto repleto de novidades que exigem o acionamento de recursos e força. Analisar a capacidade de resiliência (como superação de adversidades frente a um novo evento estressor) produz efeitos importantes no desenvolvimento do sistema familiar (Paludo \& Koller, 2007).

Um processo terapêutico bem-sucedido gera uma sensação de aumento de força pessoal. Sendo assim, torna-se fundamental fortalecer o que está funcionando bem. Ao dar-se conta de que consegue lidar bem com alguns eventos complicados, a pessoa passa a se perceber responsável por seu próprio processo de mudança. Com isto, passa a buscar recursos utilizados na sua história pessoal e familiar (O'Hanlon \& Weiner-Davis, 1997; Paludo \& Koller, 2007). Essa noção de responsabilidade faz com que a pessoa identifique sua contribuição para a manutenção do problema e busque agir de forma diferente no futuro (Gillham \& Seligman, 1999).

Outro aspecto dessa abordagem é o acesso às crenças, percepções e práticas colocadas em ação pela coparentalidade, pois isto fornece aos terapeutas um material rico para fortalecer ou (re)construir uma aliança coparental. $\mathrm{O}$ trabalho sobre temas da coparentalidade surge como guia e organiza a família ao longo do seu ciclo vital (McHale et al., 2004). Esse trabalho ainda pode ser realizado através da ampliação do contexto no qual os problemas estão sendo explicados. Ou seja, ao perceberem que uma determinada dificuldade não é resultado somente da interação do casal, mas reflete expectativas das famílias de origem e da sociedade, as pessoas sentem-se mais livres para mudar de postura e modificar seu padrão de interação. Assim, quando o casal discorda sobre a forma de criação dos filhos, é interessante explorar se esse conflito não está refletindo valores sociais e familiares sobre papéis e funções parentais (McHale et al., 2004).

A terapia no momento de estruturação da coparentalidade, portanto, pode ser um recurso para a discussão e a compreensão da perspectiva do outro, ampliando a intimidade do casal. Parece ser interessante auxiliar o casal a não antecipar algumas decisões práticas, aguardando o momento para resolução de algum impasse. Dessa forma, o foco terapêutico desloca-se para questóes relativas à capacidade de apoio mútuo, às habilidades de manejo de conflitos ou para a discussão de características individuais.

Compreendendo a relação de coparentalidade de forma mais ampla, é possível que três assuntos focais surjam no contexto clínico de casais com o primeiro filho. São eles: 1) a regulação do distanciamento com as famílias de origem; 2) a definição do espaço de trabalho e de cuidados com a criança; 3) a reestruturação psicológica exigida pela absorção de novos papéis. $O$ foco terapêutico da psicologia positiva visa a auxiliar as pessoas a identificar suas forças mais do que apontar suas fraquezas. A pessoa que vem à terapia deve ser conduzida a perceber de que forma 
atingirá sucesso e como poderá utilizar esses mesmos recursos frente a dificuldades e limitações (Miller, 2003). Os profissionais devem estar atentos à visão orientada ao problema (ainda predominante na clínica) e, além de desenvolverem os objetivos terapêuticos específicos de cada caso, identificar recursos e competências já acionados pelos sistemas para superar dificuldades que efetivamente já foram vencidas (Rafuls, 2000).

\section{O PROCESSO TERAPÊUTICO}

Questôes relativas aos vínculos e laços do casal com as famílias de origem costumam aparecer no processo terapêutico. A forma como se estruturaram e organizam como uma família para ampliar o espaço e permitir a inclusão da criança está intimamente relacionada às interações prévias como casal e deste com as famílias de origem. Os tipos de vínculos adotados pelos pais são definidos desde suas experiências anteriores e não são determinados somente pela interação com os pais na tenra infância. $\mathrm{O}$ desenvolvimento saudável está relacionado às trocas das crianças com pais sensíveis e responsivos às suas demandas. Entretanto, as mudanças continuam durante todo o ciclo vital e tornam-se possíveis por meio do relacionamento do indivíduo com outros contextos e ambientes.

Uma patologia esconde e reflete uma intrincada rede de relações, que envolve a família nuclear e as de origem (Groisman, 2006). O padrão relacional que era seguido na origem se reproduz na interação do casal e, por conseguinte, na forma de agir com seus próprios filhos, inserindo-se na história emocional de todos os envolvidos. Curran, Hazen, Jacobvitz e Feldman (2005) investigaram como as representações destas famílias de origem influenciam na manutenção do casamento. Para tal, descreveram os três tipos principais de apego (seguro, resistente e ansioso e ansioso com evitação) relacionando-os às estratégias de negociação estabelecidas pelos casais. Os resultados indicaram que a preocupação com a manutenção do casamento envolvia as formas pelas quais os casais trocavam informaçôes sobre a manutenção da intimidade, incluindo a discussão de problemas e tentativas de mudar o comportamento do parceiro. Estes autores enfatizaram, ainda, a importância das representações das experiências com relação à família de origem na predição da qualidade conjugal no processo de transição para a coparentalidade. Experiências vividas não são necessariamente repetidas entre as gerações. A falta de lembranças e a crença de que a história da família de origem não tem importância, entretanto, atuam como preditores na dificuldade de manter o vínculo conjugal. Lembranças negativas não são sinônimas de dificuldades na manutenção do casamento. Ao 
contrário, elas podem servir de contramodelo, capacitando o casal a lidar com os desafios esperados em famílias em transição.

A terapia deve considerar a influência de pelo menos três gerações do casal, pois a história familiar influencia os relacionamentos de todas as pessoas, independente das suas idades. Se possível, a presença dos avós pode ser uma ferramenta útil para o processo terapêutico. $\mathrm{O}$ relacionamento pai-mãe-filho surge no intercâmbio permanente dessas pessoas com a bagagem trazida da família de origem, do relacionamento e da identificação com seus respectivos pais. A separação da família de origem e a nuclear, em certo grau, torna-se fundamental na fase de adaptação ao nascimento do filho (Groisman, 2006). Na construção da coparentalidade é evidente a participação e influência das famílias de origem (Menezes \& Lopes, 2007). Além dos modelos adotados pelos novos pais, a rede de apoio familiar precisa ser acionada nesse período de readaptação. Uma mudança ampla e favorável ao desenvolvimento da criança, envolvendo toda a família extensa, ocorre mais em famílias cujos pais tenham interações mais harmoniosas (Talbot \& McHale, 2004). O fato de ter parentes presentes, sejam estes pais, avós, tios ou primos, permite uma vivência saudável desse período a toda família.

\section{A DEFINIÇÃO DO ESPAÇO DE TRABALHO E DE CUIDADOS COM A CRIANÇA}

A terapia deve considerar que a coparentalidade é demarcada de forma mais clara na atualidade. Se pai e mãe consideram-se responsáveis pela decisão de ter filhos, a terapia passa a ser um contexto de elaboração das mudanças e consequências envolvidas na criação dos filhos. A necessidade de estabelecer um espaço mínimo de diálogo é fundamental para a constituição de um campo saudável para a criação dos filhos. A presença de concordância é fundamental em casais modernos, em que ambos os cônjuges trabalham fora, havendo uma maior divisão dos cuidados com os filhos e das tarefas delegadas ao homem e à mulher no espaço de convivência (Gomes \& Resende, 2004). Espera-se que as mulheres mantenham os papéis de profissional e esposa, agregando a esses o papel de mãe (Ahlborg et al., 2005). Portanto, a chegada da criança pode ser percebida como uma ameaça à carreira profissional e à intimidade conjugal, além de poder desencadear sentimentos de incapacidade, baixa autoestima e desesperança. Aos papéis de profissional e marido o homem também agrega o papel de pai (Gomes \& Resende, 2004).

As exigências atuais, somadas ao desejo de realização pessoal e profissional, demandam uma sobreposição de papéis e se refletem na dinâmica subjetiva e familiar. $\mathrm{O}$ processo terapêutico deve estar atento à manutenção das identidades 
profissionais dos pais, abrindo espaço para cuidados com o(a) filho(a). Persistir na manutenção da vida profissional em tempo integral envolve partilhar com outros membros da família, mesmo que temporariamente, os cuidados com os filhos.

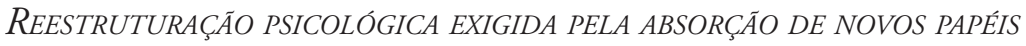

Identificar uma gravidez é diferente de assumir a parentalidade. Terapeutas atentos a essa diferença podem auxiliar na captação de recursos (internos e externos), permitindo uma maior tranquilidade nesse processo. Menezes (2006) salientou inúmeros fatores que contribuem para a adaptação psicológica de um casal no nascimento do primeiro filho. Entre as diversas possibilidades, essa fase pode ser vista tanto como uma oportunidade de crescimento e fortalecimento de vínculos quanto como um motivo de desentendimento e distanciamento do casal. A característica que parece mais determinante da forma como cada casal vivencia essa fase de transição é a qualidade de sua relação conjugal antes do nascimento. A história dos cônjuges, a intensidade e qualidade da interação afetiva são fundamentais para definir a forma como cada casal age nesse momento de adaptação.

Durante a gestação, a reflexão sobre a descendência e as idealizações depositadas na criança que está por nascer pode ser um campo rico para o trabalho terapêutico. A inclusão ou apenas o questionamento sobre a entrada de um terceiro na díade conjugal pode acionar relaçôes vinculares que vêm se constituindo ao longo do desenvolvimento de cada indivíduo. Anton (2006) afirmou que o nascimento de um bebê pode suscitar ciúme em qualquer uma das partes envolvidas. Somente pessoas que estão bem como indivíduos conviverão bem com momentos de exclusão nas relações em função das triangulações que passam a se estabelecer na dinâmica familiar. As vivências anteriores de cada um influenciam e definem como essa realidade passará a ser negociada pelos participantes da nova família.

Os terapeutas devem também perceber que atitudes de intolerância com o cônjuge podem indicar falta de modelos quanto a como agir frente ao aumento do estresse e conflito conjugais, pois demonstram menos recursos para lidar com os desafios que surgem no nascimento do bebê. Explorar em terapia o relacionamento da família nuclear e de origem de cada cônjuge antes do nascimento pode permitir o acesso a legados e segredos, a expectativas depositadas no novo casal è à construção de novos limites e fronteiras que permitam o desenvolvimento saudável dos sistemas. As referências internas dos cônjuges podem gerar impasses na relação, pois cada um pode perceber seu modelo como a única possibilidade e não perceber as diferenças (que podem ser sutis) do modelo do outro. A partilha de expectativas 
e a construção de intervenções conjuntas podem atuar como reorganizadores do casal nesse momento. Os terapeutas podem promover novas formas de lidar com as dificuldades, ao trabalhar o fato de que ser pai ou mãe envolve apoio, honestidade e ansiedade, bem como a criação do espaço de coparentalidade (Moloney, 2003).

A avaliação do relacionamento conjugal pré e pós-nascimento da criança pode permitir que o(a) terapeuta acesse possíveis aspectos que influenciam a avaliação positiva ou negativa da vida em família. Focalizar as intervenções terapêuticas nas interações conjugais pode permitir o acesso ao mundo subjetivo de cada membro do casal e também a criação de um território seguro para lidar com expectativas frustradas e sonhos idealizados. A comunicação livre (abertura e sinceridade na troca de informações) entre os dois membros do casal é o regulador desse processo. Através dela se estabelecem os consensos que atuam como mediadores dos comportamentos de cada um dos cônjuges especialmente na constituição da coparentalidade.

Ainda para colaborar com o desenvolvimento desses novos papéis, o resgate da autoestima pode ser útil clinicamente. Os momentos de maior satisfação da vida de uma pessoa são os momentos nos quais atinge/conquista algo. A compreensão do período de adaptação ao nascimento do bebê como um período de busca por uma nova organização familiar pode auxiliar o acionamento de habilidades pessoais e familiares (Gillham \& Seligman, 1999).

\section{Consideraçốes Finais}

O nascimento de uma criança é uma mudança complexa, que tem efeitos no casal e em toda a família extensa. A negociação de novos papéis gera conflitos comuns no contexto conjugal (Waldemar, 1993). Eis a importância de considerar a chegada de um bebê como um período de instabilidades, incertezas e rearranjos que pode ser acompanhado pelos terapeutas.

A coparentalidade engloba uma gama de fatores que pode ou não ser impeditiva do desenvolvimento saudável da família. Cada cônjuge necessita constituir disponibilidades internas e externas para avaliar e responder às exigências do parceiro e do filho. As bases para a construção da coparentalidade estão presentes nos pais e serão acionadas de acordo com o desenvolvimento individual e com o momento do ciclo vital do casal. A criança influencia nesse processo, inserindo suas capacidades e características no colorido da relação.

Logo, a coparentalidade constitui-se num campo relevante e atual para a prática clínica, visto que a configuração e a concepção da família contemporânea vêm se alterando em resposta às demandas da sociedade. Ela não se refere apenas 
à questão biológica de ter um filho, pois envolve também responsabilidade pelo desenvolvimento da criança. Com funções diferenciadas ou não, coabitando ou em casas separadas, o casal precisa negociar espaços práticos relacionados à criação conjunta dos filhos. A partilha de responsabilidades exige a criação de negociação entre pais, mães, tios, avós, etc., mesmo que à distância. A família extensa serve como apoio e sustentação para a nova configuração.

A terapia pode auxiliar nesse momento, criando um espaço no qual o casal possa ser flexível o suficiente para discutir questões relativas à adaptação de ambos aos novos papéis, sem que a condição de marido e mulher seja esquecida. A Psicologia Positiva integrada com a terapia familiar sistêmica pode ser uma forma de se encontrar um bom resultado clínico. Ambas buscam auxiliar a pessoa a lidar com seus problemas através do foco no positivo, nos aspectos saudáveis das interações familiares. Busca-se uma relação de "ganha-ganha", na qual todos os envolvidos no processo terapêutico percebem que suas demandas são atendidas (Shapiro, 2004).

Além da criatividade, apoio social, empatia e conversa sobre os problemas, um ingrediente importante do processo clínico é a construção das forças humanas, tais como otimismo, esperança, coragem, honestidade, realismo, avaliação de perspectivas, perseverança, humor e prazer. Estes aspectos devem ser especialmente trabalhados em pessoas que apresentam dificuldades relacionadas com alterações no ciclo vital, por exemplo o nascimento do primeiro filho (Gillham \& Seligman, 1999).

Por fim, espera-se que a partir deste trabalho tenham sido feitas contribuições quanto a alguns aspectos relacionados à constituição da coparentalidade no nascimento do primeiro filho que podem ser utilizados no processo terapêutico, especialmente através da Psicologia Positiva. A importância do estabelecimento de relações saudáveis entre o casal e seu bebê e suas interações são as bases para o desenvolvimento global saudável não somente do bebê, mas também dos adultos que se responsabilizam pelos cuidados com o mesmo.

\section{REFERÊNCIAS}

Aguiar, R. W., Lago, P. F., Strassburger, M., Blaya, D., \& Campos, M. T. (1993). Intervençôes em crises. In: Cordioli, A. C. (org.). Psicoterapias: abordagens atuais (pp. 136-145). Porto Alegre: Artes Médicas.

Ahlborg, T., Dahlöf, L., \& Hallberg, L. (2005). Quality of the intimate and sexual relationship in first-time parents six months after delivery. The Journal of Sex Research, 42 (2), 167-174. 
Anton, I. C. (2006). Casais em conflito. In: Anton, I. C. (org.). Cegonha à vista! E agora, O que vai ser de mim? (pp. 211-216). Porto Alegre: EST.

Baratojo, C., Falceto, O., \& Giugliani, E. R. (2008). Envolvimento do pai nos cuidados do seu bebê: estudo de uma amostra populacional. In: Macedo, R. M. S. (org.). Terapia familiar no Brasil na última década (pp. 157-162). São Paulo: Roca.

Carter, B., \& McGoldrick, M. (1995). As mudanças do ciclo de vida familiar. Porto Alegre: Artes Médicas.

Curran, M., Hazen, N., Jacobvitz, D., \& Feldman, A. (2005). Representations of early family relationships predict marital maintenance during the transition to parenthood. Journal of Family Psychology, 19 (2), 189-197.

Feinberg, M. E. (2002). Coparenting and the transition to parenthood: a framework for prevention. Clinical Child and Family Psychology Review, 5 (3), 173- 195.

Féres-Carneiro, T. (1992). Família e saúde mental. Psicologia: Teoria e Pesquisa, 8, 485493.

Gee, C., Scott, R., Castellani, A., \& Cordova, J. (2002). Predicting 2-year marital satisfaction from partners' discussion of their marriage checkup. Journal of Marital and Family Therapy, 28 (4), 399-407.

Gillham, J. E., \& Seligman, M. E. P. (1999). Footsteps on the road to a positive psychology. Behaviour Research and Therapy, 37, S163-S173.

Gomes, A., \& Resende, V. (2004). O pai presente: o desvelar da paternidade em uma família contemporânea. Psicologia: Teoria e Pesquisa, 20 (2), 119-125.

Groisman, M. (2006). Família, trama e terapia: a responsabilidade repartida. Rio de Janeiro: Núcleo Pesquisas.

McHale, J. P., Kuersten-Hogan, R., \& Rao, N. (2004). Growing points for coparenting theory and research. Journal of Adult Development, 11, 221-234.

Menezes, C. C. (2001). A relação conjugal na transição para a parentalidade: da gestação ao segundo ano de vida do bebê. (Dissertação de Mestrado. Curso de Pós-graduação em Psicologia do Desenvolvimento). Universidade Federal do Rio Grande do Sul, Porto Alegre, RS.

Menezes, C. C. (2006) A relação do casal quando nasce o primeiro filho. In: Anton, I. C. (org.). Cegonha à vista! E agora, O que vai ser de mim? (pp. 183-188). Porto Alegre: EST.

Menezes, C. C., \& Lopes, R. C. S. (2007). Relação conjugal na transição para a parentalidade: gestação até dezoito meses do bebê. Psico-USF, 12 (1), 83-93.

Miller, E. D. (2003). Reconceptualizing the role of resiliency in coping and therapy. Journal of Loss and Trauma, 8, 239-246.

Moloney, L. (2003). Having children and sharing the parenting. Journal of Family Studies, 9 (2), 153-159. 
O’Hanlon, W. H., \& Weiner-Davis, M. (1997). En busca de soluciones. Barcelona: Paidós.

Paludo, S. S., \& Koller, S. H. (2007). Psicologia positiva: uma nova abordagem para antigas questões. Paidéia, 17 (36), 9-20.

Piccinini, C., Silva, M., Gonçalves, T., \& Lopes, R. (2004). O envolvimento paterno durante a gestação. Psicologia: Reflexão e Crítica, 17, 303-314.

Pires, E. K. P. (2008). Talassemia e o ciclo vital. In: Macedo, R. M. S. (org.). Terapia familiar no Brasil na última década (pp. 221-231). São Paulo: Roca.

Pittman, F. (1994). Mentiras privadas: a infidelidade e a traição da intimidade. Porto Alegre: Artes Médicas.

Rafuls, S. E. (2000). Thinking competence: an exercise in teaching and training. Journal of Family Psychotherapy, 11 (2), 61-65.

Sattler, M., Eschiletti, L. L., Bem, L. A. D., \& Shaefer, M. (1999). O ciclo de vida do casal. Pensando Famílias, 1, 41-47.

Seligman, M. E. P. (2002) Positive Psychology, Positive Prevention, and Positive Therapy. In: Snyder, C. R., López, Shane J. Handbook of Positive Psychology (pp. 3-9). Okford: Oxford University Press US.

Shapiro, A. (2004). The theme of the family in contemporary society and positive family psychology. Journal of Family Psychotherapy, 15, 19-38.

Talbot, J. A., \& McHale, J. P. (2004). Individual parental adjustment moderates the relationship between marital and coparenting quality. Journal of Adult Development, 11 (3), 191-205.

Van Egeren, L. A., \& Hawkins, D. P. (2004). Coming to terms with coparenting: implications of definition and measurement. Journal of Adult Development, 11 (3), 165-178.

Waldemar, J. O. (1993). Terapia de casal. In: Cordioli, A. C. (org.). Psicoterapias: abordagens atuais (pp. 165-180). Porto Alegre: Artes Médicas.

\section{Notas}

1 Reforça-se que neste artigo o foco será somente em casais heterossexual em co-habitação.

Recebido em 2 de fevereiro de 2009 Aceito para publicação em 8 de dezembro de 2010 